\title{
Agroecologia: as coisas em seu lugar (A agronomia brasileira visita a terra dos duendes)
}

Zander Navarro ${ }^{1}$

\section{Resumo}

Agroecologia é palavra cujo uso tem se expandido nos anos recentes. Seu significado não é preciso e a literatura sobre o assunto difunde compreensões que são principalmente retóricas. No entanto, foi institucionalizada em lei em 2012. O artigo propõe uma interpretação crítica sobre o tema. A primeira seção descreve abreviadamente a passagem de um período onde existiam diferentes modelos competidores em "agricultura alternativa" para a tentativa de englobar aquelas propostas de ecologização da agricultura sob o guarda-chuva da agroecologia. A segunda parte analisa o esforço de agroecologistas de revestirem de uma aura científica o que está sendo feito sob tal nome, concluindo, contudo, que a agroecologia não tem ainda nenhum conteúdo propriamente científico. A terceira e última seção do artigo propõe desvendar este teorema, sugerindo que a agroecologia, tal como ocorre no Brasil, é principalmente um estratagema político de confrontar o dominante padrão técnico da agricultura moderna.

Palavras-chave: Agroecologia. Agricultura alternativa. Princípios da agroecologia. Crítica à agroecologia.

\begin{abstract}
The use of the word agroecology has been expanded in recent years. Its meaning is not precise and the literature about it disseminates understandings that are mainly rhetoric. Even so, it was institutionalized in law in 2012. The article proposes a critical interpretation about the subject. The first section briefly describes a passage from a period when co-existed different models of agricultural ecologization competing between them to an attempt to encompass all of them under the umbrella of agroecology. The second section analyses the efforts of agroecologists of impinging a scientific aura on what has been made under the name of agroecology. This section concludes, however, that it does not have any scientific content so far. The third and last section proposes clarifying this theorem and it suggests that agroecology, as it has been under operation in Brazil, is mainly a political stratagem to confront the technical pattern of modern agriculture.
\end{abstract}

Keywords: Agroecology. Alternative agriculture. Principles of agroecology. Critique of agroecology.

\footnotetext{
${ }^{1}$ Pesquisador, EMBRAPA Estudos e Capacitação. As opiniões contidas neste artigo são de exclusiva responsabilidade do autor e não refletem, necessariamente, as opiniões da instituição à qual o autor está vinculado. zander.navarro@embrapa.br
} 


\section{Introdução}

Estar comandando a 'teoria' e o 'método' é ter se tornado um pensador consciente, alguém que trabalha e está ciente dos pressupostos e das implicações do seu significado. Mas ser comandado pela 'teoria' e o 'método' significa simplesmente ter deixado de funcionar (WRIGHT MILLS, 1959, p. 226, grifo nosso).

Intensificando-se nos anos do presente século, o termo "agroecologia" e seus correlatos (como "transição agroecológica" ou a obrigatória e quase-religiosa expressão "princípios da agroecologia") têm multiplicado a sua recorrência, na voz de distintos atores sociais ou em documentos de diferentes instituições. A vasta maioria dessas manifestações é surpreendente, pois são obviamente equívocas e sem nenhum fundamento consistente, empírico ou teórico-metodológico. É um acúmulo de referências que parece informar aos observadores mais desavisados que, de fato, aquela palavra conteria em seu suposto significado não apenas alguma problemática teórica (ou até uma ontologia), mas também variados tipos de processos reais (tecnológicos, sociais ou outros) com alguma relevância "emergente". Seriam processos, conforme sugerem seus proponentes, que apontariam para tendências de mudanças desejadas e recomendáveis, assim como também estariam se concretizando em termos práticos nos sistemas agrícolas do país.

Entre inúmeras ilustrações possíveis, mas circunscrevendo-se apenas a exemplos nacionais nesta introdução, examine-se um documento do Instituto de Pesquisa Econômica Aplicada - IPEA - dedicado a analisar "O comércio internacional e a sustentabilidade socioambiental no Brasil" (INSTITUTO DE PESQUISA ECONÔMICA APLICADA², 2011, p. 1). O texto destina-se a refletir sobre as relações entre as tendências comerciais brasileiras e suas implicações socioambientais. Inicialmente informa que:

Desde os tempos do Brasil colônia, a pauta de exportações brasileira foi concentrada em produtos primários e commodities. Neste texto argumentase que apesar de o cultivo desses produtos gerar ganhos econômicos e empregos, bem como trazer divisas para o país, a inserção internacional

\footnotetext{
${ }^{2} \mathrm{O}$ Instituto de Pesquisa Econômica Aplicada será, doravante, registrado apenas como IPEA. N. R.
} 
fortemente calcada no fornecimento de commodities gera uma série de impactos negativos do ponto de vista ambiental e social que geralmente não entram de maneira adequada nas tomadas de decisões públicas e privadas (IPEA, 2011, p. 1).

O artigo discute então as particularidades recentes do comércio internacional, sempre insinuando que existiria "algo errado" com o padrão de desenvolvimento agrícola brasileiro. Ao final, a sentença acusatória se torna explícita e os autores recomendam, ao discutir as "implicações para as políticas públicas" de sua análise, que "[...] a partir da construção coletiva de uma visão holística sobre o assunto [sic], caberia à sociedade debater sobre as vantagens e as desvantagens de se adotar tal modelo de inserção internacional" (IPEA, p. 10). E concluem, apelando para uma retórica rebaixada, pois a afirmação surge levianamente, sem nenhuma explicação, sequer com alguma indicação bibliográfica. Aponta o texto que:

[...] parece desejável criar outros estímulos para aumentar o valor agregado dos produtos brasileiros. Uma possível estratégia nessa direção seria a especialização para ocupar nichos de mercado específicos, uma vez que existe uma crescente demanda, ao menos nos países centrais, para produtos ambientalmente e socialmente adequados. Nesse sentido, as políticas agrícolas poderiam incentivar a transição para outros métodos de produção, como aqueles que se baseiam na agricultura orgânica ou em princípios da agroecologia (IPEA, 2011, p. 11, grifo nosso).

O que significaria esta transição proposta ou, mais especificamente, a palavra agroecologia (e seus mágicos "princípios"), para os autores do documento que tão enfaticamente condenam o desempenho da agropecuária brasileira? Não são explicados no texto, em nenhuma parte, assim sugerindo que existiria alguma "informação consolidada" sobre tais termos e seus respectivos significados e, portanto, sendo conhecimento presumivelmente notório, não requer explicação alguma.

Ainda mais espantosamente, em face de sua origem institucional, documentos preparatórios para a reunião Rio+20 (junho de 2012), organizados pelo CDES e pela Secretaria Geral da Presidência da República seguem a mesma toada. Um deles, intitulado "Agendas nacionais de desenvolvimento sustentável", que circulou amplamente pouco antes da conferência, apontava que as diretrizes de um futuro e hipotético "Acordo sobre desenvolvimento sustentável" deveriam incentivar 
"práticas e tecnologias agrícolas voltadas à conservação dos recursos naturais, à agroecologia [...]", novamente sem nenhuma explicação acerca do significado desse último termo inserido na proposição - como se fosse conhecido de todos. Como terceira e reveladora ilustração, cite-se um recente edital do MDS/CNPq (número 24/2013, lançado em 02/09/2013), o qual, em seu regulamento, ao citar as linhas temáticas sob as quais seriam aceitas as propostas de pesquisa, lista no item sobre "segurança alimentar e nutricional" que caberiam projetos destinados à "avaliação de experiências na área de abastecimento alimentar, com base no fortalecimento da agricultura familiar, da agroecologia e da agroindústria familiar" (p. 13). Mesmo sendo insistente, reafirma-se: sem que o edital, em nenhum momento, explique aos candidatos o que seria "agroecologia". E contando com a chancela conjunta do CNPq, se esperaria que o termo pudesse ser pelo menos enquadrado na tabela das áreas de conhecimento usualmente utilizada por este Conselho. Se fossem instituições que soubessem o que estão propondo, deveria ser imediata a alocação científica da agroecologia, mas não existe a indicação no edital citado.

Outro edital recente do CNPq, subscrito por cinco ministérios (Chamada no 81/2013, de 26/09/2013), destinado a apoiar projetos destinados à "construção e socialização de conhecimentos e práticas relacionados à Agroecologia e aos Sistemas Orgânicos de Produção [sic]" cita, em 27 páginas do edital, 77 vezes os termos "agroecologia", "enfoque agroecológico", "transição agroecológica", "base agroecológica", mas também não oferece nenhuma indicação sobre o que significariam. À página 16, o edital cita que as equipes proponentes devem demonstrar "competência" em diversas áreas, incluindo agroecologia (desta vez citada em letra minúscula), insinuando que esta seria uma "área de conhecimento". E sugere que as propostas devem incluir "cursos de qualificação e de formação" que envolvam "temáticas específicas fundamentadas nos princípios, conhecimentos e práticas relacionadas à agroecologia" (p. 16 do edital). Como organizar cursos sobre "princípios e conhecimentos" inexistentes? E não se indica no edital um item bibliográfico sequer para apontar os conteúdos de tais termos e expressões. 
Notar a gravidade de serem todos os exemplos oriundos de organismos do Estado, os quais, supostamente, deveriam adotar extrema cautela em sua ação, se inovações conceituais, como a citada, ainda não encontram nenhuma âncora substantiva na literatura a respeito ${ }^{3}$.

A culminância dessa marcha insensata na direção de propor o que nunca é definido deu-se com a inacreditável instituição da "Política Nacional de Agroecologia e Produção Orgânica", promovida pelo Decreto número 7.794, assinado em 20 de agosto de 2012. A insensatez (ou má fé) existe porque no próprio corpo do documento legal é citado que a "produção de base agroecológica" será entendida (artigo $2^{\circ}$, inciso III) como "aquela que busca otimizar a integração entre capacidade produtiva, uso e conservação da biodiversidade e dos demais recursos naturais, equilíbrio ecológico, eficiência econômica e justiça social ( $\mathrm{sic}$ ), abrangida ou não pelos mecanismos de controle que trata a Lei oㅜ 10.831, de 2003". Torna-se assim manifesta a tentativa de forçar a associação entre a "agricultura orgânica" e a "agroecologia", como se similares ou iguais fossem as expressões, pois a Lei oㅡ 10.831, referida no corpo do decreto (e o citado inciso), de fato, refere-se exclusivamente à "agricultura orgânica", sem nenhuma referência à agroecologia. Ora, como a primeira apresenta um histórico relativamente consolidado de significado e desenvolvimento, passando pelas práticas agrícolas e chegando à certificação, sem nunca ter se ancorado na "agroecologia", conclui-se que o recémassinado decreto, assim como as mencionadas ilustrações são, de fato, um mal disfarçado intento de criar um "fato consumado", forçando a existência de um ente que, até aqui, ninguém saberia realmente sequer definir. Se for assim, certamente terá sido, sobretudo, uma ação política, sem qualquer intenção técnico-agronômica

\footnotetext{
${ }^{3}$ E o que dizer da meta do "Programa Nacional de Alimentação Escolar" (PNAE), que pretende exigir certa proporção de "alimentos agroecológicos" em suas aquisições? Como impor este requerimento quando sequer se sabe o que significa agroecologia, conforme será discutido neste artigo? E como não existem limites, a chamada pública no 13 do MDA (outubro de 2013) reforça a tendência, prometendo cem milhões de reais em inúmeras atividades, inclusive citando que o público beneficiário seriam 23 mil famílias "que já desenvolvem a produção agroecológica ou estão em transição". Faltou, contudo, ao Ministério identificar essas famílias, demonstrando porque sua produção seria "agroecológica" ou "em transição". Novamente, reina o silêncio sobre o significado da misteriosa palavra.
} 
(menos ainda científica), cujos objetivos permaneceram ocultos. Ou o Estado brasileiro sancionaria um decreto propondo algo ainda desconhecido, o que se torna claro na obscura enunciação da "produção de base agroecológica" acima referida? Algum especialista em formatos tecnológicos agrícolas seria capaz de explicar com objetividade e exemplos práticos o que está exposto no decreto, acima reproduzido, inclusive atendendo aos objetivos de "justiça social"?

Portanto, como sempre, lembrando a velha pergunta antecedente dos advogados, faltaria responder - a quem interessa tudo isso? Quem explicaria o significado da palavra agroecologia, cuja repetição se amplia a cada dia nos documentos oficiais, como se fosse consensual e indubitável o entendimento conceitual sobre o termo? Seria mesmo notório o seu significado, todos de fato saberiam sobre o que se trata? Que palavra é essa que amplia a sua repetitiva menção pública, mas permanece camuflada a sua conceituação, se alguma existir? Qual a rationale de organismos do Estado, ao citarem somente de passagem aquele termo, sem nenhuma justificativa conceitual? Por que forçar sub-repticiamente a reiteração de um termo não explicado, parecendo querer criar um fato consumado, como fruto de um estratagema goebbelsiano ${ }^{4}$

Talvez uma explicação possível, embora distante de qualquer racionalidade científica, possa ser obtida em manifestação contida em documento extraído de evento realizado pela empresa pública de extensão rural da Bahia, durante a "6" . Feira da Agricultura Familiar", realizada em agosto de 2011, na cidade de Morpará, pequeno município situado no Vale do São Francisco. O técnico da Empresa Baiana de Desenvolvimento Agrícola (EBDA) responsável pela "palestra sobre agroecologia", talvez sem corar, não teve dúvida alguma sobre a conceituação, afirmando que:

[...] Agroecologia ou agricultura natural é antes de tudo um sentimento bom, um sentimento de agradecimento a Deus, um sentimento de estar vivo e

\footnotetext{
${ }^{4}$ Como se insistirá neste artigo, não sendo uma teoria ou ancorando-se em alguma estrutura teórica, além de distante de qualquer "problemática" científica, como poderia a agroecologia ser oferecida como disciplina em algum curso de pós-graduação? Ou o absurdo de terem sido formados cursos de pós-graduação em agroecologia, este não sendo um campo da ciência?
} 
amar todas as formas de vida desse planeta [...]. Agroecologia não é plantar para vender, e sim plantar para si e sua família, e para não ter que comprar produtos contaminados por agrotóxicos. Vender sim, mas vender somente 0 excedente [...]. Praticar agroecologia é respeitar os nossos antepassados, e respeitar o conhecimento e práticas agrícolas utilizadas pelos primeiros agricultores desse planeta. É olhar para o céu todos os dias, ver a lua, e escutar o que ela quer nos falar [...]. Agroecologia é isso, é respeito a Deus e todas as formas de vida de sua criação, é não caçar, é não derrubar e queimar as matas, é não fazer carvoeiras, é não usar agrotóxicos, adubos químicos e qualquer produto industrial que contamine o meio ambiente [...]. Praticar Agroecologia é agradecer a Deus, quando ocorrem pragas e doenças na nossa lavoura (pulgão, cochonilha, lagarta, formiga...), pois essas pragas estão aí para nos alertar que tem alguma coisa desequilibrada na nossa lavoura por erros que estamos cometendo com o solo, práticas e técnicas inadequadas [...]. Pronto, é só isso, daí pra frente é só utilizar em seu benefício e da sua família todos os recursos naturais que estão ao seu redor [...] (EBDA, 2011).

Ante a perplexidade com a citação, mas sem comentar adicionalmente sobre o delírio acima transcrito, supostamente oferecido a agricultores por um técnico de uma empresa pública e exemplificando assim a degradação institucional a que chegou a extensão rural estatal em alguns estados, essa e as anteriores são ilustrações que demonstram a urgente necessidade de situar corretamente o termo e sua história. E também (e, sobretudo) apontar o seu real significado - se algum existir.

Este curto artigo é um primeiro esforço analítico do autor para debater a agroecologia e se organiza em três seções ${ }^{5}$. Primeiramente, sintetiza os esforços

\footnotetext{
${ }^{5}$ Minha trajetória pessoal nesse campo social específico não merece detalhamento, pois este é artigo científico. Contudo, como esta é uma discussão envenenada, sujeita a discussões morais e emocionais, movidas por dogmas irremovíveis (como bem ilustrado na última citação), talvez seja relevante, pelo menos, citar que minha entrada como pesquisador na Sociologia Rural, na segunda metade dos anos 1970, foi pelo lado da contestação radical à chamada "agricultura moderna", posicionamento analítico que ainda não abandonei inteiramente, pois julgo ser esta última enraizada em um formato tecnológico insustentável (bem como o próprio padrão civilizatório correspondente), mesmo reconhecendo que não temos ainda, de fato, nenhuma alternativa disponível. Fruto dessa visão de mundo, acompanhei, e de perto, como pesquisador, inúmeras experiências em "agricultura alternativa", sobretudo no Sul do Brasil, desde 1981 (ao retornar de meu doutoramento, realizado no exterior). A análise oferecida neste curto artigo, portanto, reflete experiências pessoais que eu realmente vivenciei, não se tratando de análise livresca, mas especialmente prática. Como ilustração emblemática, entre inúmeras que poderia oferecer, cito que o único livro conhecido que tem algum estofo científico sobre o tema, escrito, sem surpresa, por um ecólogo com trajetória universitária e seguidor dos cânones científicos mais rigorosos (GLIESSMAN, 2000) somente existe em português porque coordenei toda a engrenagem que levou à sua publicação, desde a autorização do autor (que me foi oferecida pessoalmente) ao livro impresso, listado na série "Estudos Rurais", da UFRGS, que foi fundada por mim, em esforço isolado e individual, e contra todas as adversidades que então existiram para viabilizá-la.
} 
sociais e políticos que em aproximadamente vinte anos alçaram a palavra "agroecologia" a um relativo conhecimento público, o que permitiria inclusive, de acordo com seus proponentes, mencionar o termo sem a necessidade de explicações adicionais, como se fosse uma ciência ou um conceito de amplo conhecimento, na sociedade ou, pelo menos, entre os especialistas. Nessa seção apenas se indicará, esquematicamente, um conjunto de fatos e desenvolvimentos que animaram o surgimento da agroecologia no Brasil como um termo essencialmente destinado a criar um ilusionismo público, pois encerraria em si mesmo um suposto conteúdo relacionado a uma "nova agricultura" - o que nem remotamente existe. Mais ainda, proclamam seus aderentes que a palavra também incluiria um conteúdo científico. Assim, a segunda seção discute exatamente essa pretensão exaustivamente repetida por aqueles que dizem professar adesão à agroecologia: é uma ciência, ainda que emergente?

Finalmente, antecedendo as conclusões, a terceira e última seção do artigo propõe uma solução a esse teorema, sugerindo que o termo agroecologia, tal como vem sendo operado no Brasil, de fato, é apenas uma ocultação de natureza primordialmente política, embora apresentado publicamente sob um falso manto, aquele que buscaria um "novo formato tecnológico", assentado em alguma enigmática ciência nunca esclarecida. Mas a razão principal para o seu uso público seria outra, relativamente distinta, que seria desenvolver esforços e ações políticas anticapitalistas, via a crítica da chamada agricultura moderna. É essa a única explicação possível para o contrabando do termo "agroecologia" no recente decreto assinado, usando a agricultura orgânica como trampolim para buscar algum tipo de legitimidade institucional e suposto reconhecimento público - não pela difusão de um conhecimento realmente novo, que tenha alguma concretude, mas pela mera repetição do termo ${ }^{6}$.

\footnotetext{
${ }^{6}$ É incompreensível que o Planalto tenha assinado o citado decreto, pois sugere uma decisão marcada ou por má fé ou, então, por espantosa ingenuidade. Como imaginar que nossa maior autoridade tenha cometido tal erro e qual teria sido a justificativa que o sustentaria?
} 
Como a observação acima soará para alguns como "acusação autoritária" (o que não é), é preciso insistir que em um regime democrático, como o brasileiro, aquelas ilustrações e, particularmente, o decreto, são manobras políticas legítimas, ainda que aéticas e talvez até imorais. Mas legítimas porque concretizadas à luz do dia, e contando até mesmo com a bênção de nossas maiores autoridades. Contudo, são iniciativas e procedimentos pelo menos aéticos, porque sem ter sido tornada pública a intenção efetiva de seus formuladores principais, incapazes de propor algo novo em termos de tecnologia agrícola sob o rótulo da "agroecologia", sem rodeios ou circunlóquios diversionistas, mas precisando até mesmo ser carregado pela "agricultura orgânica". Como não tem ocorrido a honestidade intelectual dos principais defensores da agroecologia de se apresentarem sem disfarces, diversos outros profissionais e setores sociais têm sido objeto, concretamente, de clara manipulação política - incluindo técnicos ligados às instituições do Estado dedicadas à pesquisa agrícola ou à produção do conhecimento científico, como ilustrado acima. Ainda mais perverso: inúmeras famílias rurais pobres têm sido recrutadas, seduzidas pela promessa de terem acesso à via tecnológica que Ihes garantiria a prosperidade - situação que os membros do campo agroecológico ainda não conseguiram concretizar no mundo rural brasileiro.

\section{Síntese histórica: a construção social e política do termo "agroecologia"}

Como chegamos à atual situação, na qual se difunde o termo agroecologia sem nenhuma explicação apropriada, forçando a criação de uma orwelliana "nova verdade" com tinturas meramente retóricas, sem que o seu real significado seja conhecido? Nesta seção esboça-se, sucintamente, o caminho histórico que, nos últimos trinta anos (aproximadamente), uma ação política de contestação à chamada agricultura moderna foi sendo desenvolvida, até que chegasse, no último decênio, à construção de uma nova estratégia, aquela que centraliza tais esforços em torno da expressão agroecologia. Como se perceberá, esse esboço é extremamente simplificado, por razões de espaço, e representa um primeiro esforço de síntese dos 
acontecimentos, ocorridos durante um longo período de tempo e durante o qual o Brasil experimentou profundas mudanças econômicas, políticas e institucionais (para não citar as mudanças tecnológicas operadas na economia agropecuária, especificamente). Sendo uma brevíssima síntese, apresenta-se muito mais como um comentário introdutório ao assunto, o qual deverá ser aprofundado por outro texto mais alentado, em preparação ${ }^{7}$.

O ponto de partida combina a convergência histórica entre um contexto político (os anos finais do regime militar, especialmente a partir do emblemático ano de 1979) e um processo econômico que foi a intensa estratégia de modernização da agricultura brasileira na década de 1970. Nesse último período (grosso modo, entre 1967/68 e o ano de 1981), houve um primeiro esforço concertado de modernização da agricultura brasileira, seguindo os ditames do "padrão moderno" que caracterizou a transformação produtiva das agriculturas norte-americana e europeia, depois da II Grande Guerra. Realizado sob o constrangimento de um regime ditatorial, como seria esperado no Brasil esse processo assumiu facetas discriminatórias, beneficiando privilegiadamente certos tipos de produtos, determinadas regiões e, em especial, alguns grupos de produtores. Como a literatura demonstrou à exaustão, a transformação produtiva e tecnológica daqueles anos, ao operar seletivamente, alargou as diferenças sociais do mundo rural brasileiro. Mas é relevante realçar que também naquela década formou-se uma geração de produtores que seria (assim como os seus sucessores) crescentemente movida por um novo ethos econômico. Gradualmente, seus membros deixaram de ser os (negativamente nomeados) "fazendeiros ou latifundiários" do passado, para passarem a ser os produtores rurais movidos pela incessante busca de maior eficiência decorrente da abertura às inovações, essas últimas sendo o motor principal para a produção de riqueza econômica.

\footnotetext{
${ }^{7}$ Não se desconhece a literatura a respeito e a diferença de qualidade analítica entre os autores. Como este artigo é não mais do que uma brevíssima introdução, não são citados sequer os mais influentes livros e artigos sobre agroecologia no Brasil, o que será objeto de análise futura em outro estudo mais amplo.
} 
A ampliação da seletividade social despertou setores sociais politicamente dispostos à esquerda, os quais, também motivados por outras características negativas, como a depredação ambiental e outros "impactos sociais da modernização agrícola" (MARTINE; GARCIA, 1987), passaram a desenvolver diversas iniciativas de contestação ao novo padrão tecnológico imposto às regiões agrícolas. Foram possibilidades de ação política (que também se apresentavam então como sendo "técnico-agronômicas") que se tornaram facilitadas com o enfraquecimento do regime militar, depois de 1979 - até a sua conclusão e passagem a um regime civil, a partir de 1985. Ainda assim, nos anos oitenta, as ações de antagonismo ao padrão técnico dominante que foram desenvolvidas em algumas regiões brasileiras foram escassas e circunscritas, no geral decorrentes de iniciativas de três grupos sociais principais.

Esses grupos eram formados, respectivamente, pelas ONGs do campo chamado então de "agricultura alternativa", por alguns poucos pesquisadores (incluindo cientistas sociais) das universidades e institutos de pesquisa, e o terceiro subgrupo sendo formado por minoritários setores do campo estudantil, especialmente oriundos das escolas de Agronomia. Há um quarto grupo, também numericamente pequeno, mas capaz de viabilizar consequências práticas extremamente importantes: foram os mediadores religiosos ligados à Igreja Católica, inspirados pela Teologia de Libertação. No geral, os religiosos apoiaram mais diretamente naqueles anos os esforços políticos e organizacionais realizados pelos emergentes movimentos sociais do período (movimento dos sem terra, movimento de barragens e movimento sindical). Mas como quase todos eram simpatizantes do mesmo campo partidário, foram mediadores que igualmente viabilizaram o apoio logístico às ações realizadas no campo da "agricultura alternativa".

Nessa primeira fase, aqueles grupos desenvolveram inúmeras atividades de tentar viabilizar "soluções práticas" que pudessem ser oferecidas como alternativas ao padrão moderno instalado na década anterior. Mas os resultados foram irrelevantes e raras situações concretas obtiveram algum destaque digno de menção. De fato, quase todos os atores sociais envolvidos, simpatizantes do 
nascente campo partidário hegemonizado pelo Partido dos Trabalhadores, produziram principalmente a criação de ativos políticos que pudessem beneficiar esse campo partidário, enquanto os objetivos propriamente tecnológicos e produtivos quase nunca foram alcançados. Sob o risco de uma injusta generalização que faz tabula rasa de todas as iniciativas realizadas, não se estará longe da verdade afirmar que as divulgadas experiências práticas animadas pelos profissionais (agrônomos, em particular) das diversas ONGs espalhadas em diferentes regiões produziram resultados pífios, seja em termos de garantir a adesão das famílias rurais, seja então, em termos de novas técnicas que pudessem realmente se apresentar como opções ao cardápio do formato tecnológico da agricultura moderna (ver box a seguir).

\footnotetext{
A partidarização da agroecologia: uma ilustração emblemática

Sou forçado a resgatar uma experiência pessoal, para demonstrar mais convincentemente a observação sobre os objetivos exclusivamente políticos dos esforços realizados sob o guardachuva da agroecologia, citando um exemplo paradigmático desta clivagem entre o político e o técnico-agronômico. Colaborei com a formação de uma daquelas ONGs, certamente a que se apresentava como a "mais contestadora" (e, supostamente, "mais à esquerda") do campo das ONGs da "agricultura alternativa" do Sul do Brasil - o Centro de Tecnologias Alternativas Populares, o CETAP, cuja sede sempre esteve no Alto Uruguai do Rio Grande do Sul e, sintomaticamente, a mais próxima ao MST. Acompanhei durante muitos anos as atividades do Centro, como monitor da Fundação Interamericana (IAF), organização ligada ao Congresso norteamericano que foi uma das principais financiadoras do CETAP durante os seus primeiros dez anos de existência. No período, o apoio da IAF transferiu pouco menos de um milhão de dólares ao CETAP. Em 1995, a ONG me convidou para a "avaliação dos dez anos" (como membro de uma equipe de quatro técnicos), em um exercício que me entristeceu profundamente, embora não tenha representado qualquer surpresa (pois acompanhava quase tudo realizado pelo CETAP). A avaliação foi desastrosa, não sendo capaz de descobrir uma família rural (uma que fosse) que tivesse modificado seus sistemas produtivos para uma direção mais "alternativa", por mais que os avaliadores, todos simpáticos ao CETAP, se esforçassem em demonstrar algum resultado positivo. O agrônomo que mais desenvoltamente se apresentava como porta-voz dos esforços realizados e que sempre liderou a entidade, naqueles anos, moveu-se então para o campo partidário e, em dois
} 
governos petistas do Rio Grande do Sul (1999-2002 e atualmente), conseguiu (inexplicavelmente) ser apontado como presidente da EMATER estadual. Sem nenhuma surpresa, em seus mandatos, a EMATER gaúcha passou a inscrever fantasias pueris entre seus objetivos. Seu mais recente "Relatório de Atividades" aponta que o primeiro objetivo da empresa é "Alcançar patamares crescentes de sustentabilidade nas formas de manejo dos recursos naturais e dos agroecossistemas, com base nos princípios da Agroecologia" (EMATER, 2013, p. 11, grifo nosso).

Nesta primeira fase, o termo agroecologia existiu exclusivamente em função de sua utilização pelo entomologista chileno radicado nos Estados Unidos, Miguel Altieri. Seu livro foi inicialmente traduzido por uma ONG sediada no Rio de Janeiro e exerceu uma pequena influência entre os setores sociais orbitados por aquela organização não governamental (ALTIERI, 1987). Nas situações restantes, contudo, a expressão corrente era "agricultura alternativa". Naqueles anos, inclusive, existiam disputas entre as ONGs desse campo, todas buscando a hegemonia da contestação política à agricultura moderna que havia sido difundida pelo regime militar na década de 1970. Cada uma dessas organizações, no entanto, optava por um dos modelos tecnológicos disponíveis, então chamados de "alternativos", o que criava uma nítida fragmentação entre as diferentes propostas, enfraquecendo-as, pois eram competidoras entre si.

Com o florescimento democrático posterior à Constituinte, em especial durante a década de 1990, essa fragmentação se tornou ainda mais acentuada e essas foram iniciativas que muito pouco prosperaram na primeira metade daquela década. Tal situação começou a ser modificada apenas nos anos finais daquela década, em face de duas razões principais. Primeiramente, o campo petista foi gradualmente se acercando do Estado brasileiro, sendo vitorioso em eleições municipais e algumas estaduais, antes da chegada ao Governo Federal, em janeiro de 2003. Ante essas novas possibilidades de "entrar no Estado" e ser capaz de forçar novas políticas públicas, foi sendo amadurecida entre tais setores sociais a visão pragmática acerca da necessidade de uma convergência interpretativa (ainda que apenas aparente), que eliminasse a competição entre as múltiplas visões de agriculturas ecológicas então existentes. 
A difusão do ideal da sustentabilidade e sua crescente multiplicação na agenda política dos governos, naqueles anos, apenas reforçou esta necessidade de unir aquelas diferentes visões de uma agricultura ecológica, um objetivo que era primeiramente político, antes do que técnico ou agronômico. Isso porque, se alguma chance de contestação à agricultura moderna viesse a existir em algum momento futuro, essa possibilidade dificilmente se materializaria com as disputas entre si e o então cardápio variado de diferentes "agriculturas ecológicas", algumas muito distintas entre si.

Era urgente uma palavra-unificadora que abrigasse as diferentes perspectivas existentes, uma palavra meramente classificatória em relação ao padrão dominante, que era (e continua sendo) a agricultura moderna. Nunca um conceito, como seria óbvio para todos aqueles que conhecessem o campo da agricultura chamada alternativa, em face da disparidade de interpretações e premissas que organizavam aqueles diferentes modelos que pretendem a ecologização da agricultura.

Essa possibilidade de localização de uma "palavra englobadora" concretizouse, de fato, de onde menos se esperava, sendo esta a segunda razão a ser citada. Com a crescente percepção acerca dos bloqueios (especialmente os legais) para a realização da reforma agrária brasileira e os limites à ação do MST em torno do tema, no final dos anos noventa, essa organização decidiu investir nos "pequenos produtores" (assentados ou não), tendo criado em 1998 o chamado "Movimento dos Pequenos Agricultores" (MPA). Trata-se de uma espécie de braço sindical do MST, embora sendo apresentado naqueles anos como "movimento autônomo", ainda que fosse apenas uma correia de transmissão da organização dos sem-terra.

Esse primeiro passo foi a porta de entrada, posteriormente, para a associação do MST à (internacional) Via Campesina. Através desta, houve a convergência com os autores e discussões existentes no exterior em torno da agroecologia e, gradualmente, o MST-Via Campesina aderiu à nova noção, com o duplo objetivo de manter o ideário anticapitalista típico do Movimento sob uma nova bandeira, além de manter uma narrativa destinada a mobilizar os pequenos produtores rurais. 
Com a adesão do MST, os demais atores (especialmente as ONGs mais radicalizadas e os setores estudantis) igualmente se associaram a essa noção abarcadora de agroecologia, como uma palavra que proporia um ideário tecnológico "alternativo" e contrário à agricultura moderna.8 Aos poucos, alguns técnicos, igualmente embalados por uma suave visão política à esquerda, também aderiram a esse campo político que foi emergindo, embora movidos, quase sempre, principalmente por objetivos técnicos, mas sem perceber a maquinação política que foi sendo desenhada naquele período.

Por essa razão, não será equivocado afirmar que nesses anos finais da década de 1990 e nos seguintes, estendendo-se até os nossos dias, foram socialmente enraizados aqueles três subgrupos antes citados, porém agora com objetivos, papéis e formas de ação bem mais nítidas e diferenciadas. Primeiramente, foi se organizando em nome da agroecologia um "núcleo político", formado pelas lideranças do MST, ativistas de algumas das principais ONGs mais radicalizadas (a AS-PTA à frente), também contando com setores partidários do campo petista situados mais à esquerda (capitaneados pelo chamado "núcleo agrário" do partido, totalmente hegemonizado pelo MST), além de alguns raros técnicos $\mathrm{e}$ pesquisadores que se movem exclusivamente pela política partidária, embora se apresentando como "cientistas". Esse é o grupo que desenhou a nova estratégia de combate político à agricultura moderna, para tanto usando todas as armas possíveis (como a falsa dicotomia entre "agricultura familiar" e "agronegócio", ou combatendo ferozmente as inovações tecnológicas como os OGMs, entre outros estratagemas). Crescentemente falando a mesma linguagem falseadora das chances tecnológicas da agricultura de "criar o novo", passaram a orientar e controlar politicamente a unificação do novo discurso político em torno da agroecologia. Inclusive, utilizaram

\footnotetext{
${ }^{8}$ Assim posta, esta observação histórica é insuficiente e simplificadora. Em estudo mais completo, será sempre preciso também introduzir no quadro conjuntural do final dos anos noventa, os movimentos antiglobalização, a realização dos "fóruns sociais mundiais", o baixo crescimento econômico da segunda metade daquela década, o crescimento do campo partidário petista e as influências internacionais que foram nascendo no período, inclusive a formação de um curso de pós-graduação em "Agroecologia", combinando professores da Universidade da Califórnia (como Stephen Gliessman e Miguel Altieri) e outros, como o espanhol Eduardo Sevilla Guzmán.
} 
meios diversos de intimidação política a qualquer debate que pudesse problematizar esse novo esforço de modelar uma nova ideologia sobre o desenvolvimento agrário e suas possibilidades.

Secundariamente, formou-se outro subgrupo, aqui chamado de "núcleo operacional", que foi aquele cooptado pelo primeiro, pois (quase sempre) simpatizante do mesmo campo partidário, formado principalmente por técnicos de diferentes instituições - seu papel era, nesse caso, o de produzir um verniz superficial de legitimidade científica à noção de agroecologia, reforçando assim os objetivos políticos originais. É um grupo claramente movido de longe pelo primeiro, pois usualmente seus integrantes eram ingênuos, do ponto de vista político, incapazes de perceber que seus objetivos primordiais (a "ecologização da agricultura") não são necessariamente os mesmos objetivos do antes chamado "núcleo político" - cujo objetivo primordial é combater a agricultura moderna e, como extensão lógica, os setores empresariais rurais e, finalmente, a própria ordem econômica e social dominante. E, finalmente, existe o terceiro subgrupo, o "núcleo de militantes", formado especialmente de setores estudantis e os militantes do MST, cuja missão seria destinada, sobretudo, às ações públicas (sempre incondicionais e irrefletidas) com o objetivo de conferir maior visibilidade à agroecologia. Esse terceiro grupo não era mais do que a massa de manobra destinada às manifestações públicas em torno da agroecologia.

Fechou-se assim a equação que fez nascer uma palavra, inteiramente vazia em si mesma, mas na prática auto-atribuindo-se o objetivo político de controlar espaços institucionais do Estado brasileiro. Além disso, mantinham-se metas ambiciosas, desde reorientar o conjunto das políticas públicas para o mundo rural à promoção de diversos outros objetivos que, potencialmente, organizariam a agroecologia como mecanismo de ação confrontacional em relação aos setores empresariais rurais mais dinâmicos da economia agropecuária brasileira. Em síntese: tentava-se ressuscitar a boa e velha luta de classes no campo brasileiro.

Até os nossos dias essa estratégia funcionou apenas parcialmente, com limitada repercussão - social e política. E resultados práticos entre os agricultores 
que são ainda mais raros. Por quê? Primeiramente, nem mesmo os setores majoritários do campo petista apoiaram a sua concretização, durante os mandatos presidenciais recentes, provavelmente por perceberem a crucial importância da agricultura modernizada para garantir os saldos da balança comercial. Mas não tem funcionado a contento porque, em especial, na mesma época o setor econômico "agricultura" no Brasil disparou, rapidamente alicerçando um novo padrão agrícola e agrário, centrado na inovação tecnológica, produzindo, crescentemente, mais riqueza e prosperidade nas regiões agrícolas. Por essa razão, a estratégia esboçada acima vem encontrando dificuldades sociais e políticas crescentes para ser bem sucedida, mesmo que recebendo a simpatia de alguns setores do Estado brasileiro, conforme as ilustrações registradas na introdução deste artigo. Pela mesma razão principal (o sucesso da moderna agricultura brasileira) a tentativa de concretizar a agroecologia como uma alternativa tecnológica destinada a substituir a tecnologia moderna nas regiões de produção agropecuária tem chances remotas de se tornar realidade algum dia. Até mesmo porque tal modelo alternativo, na prática, sequer existe.

Sobre os famosos "princípios da agroecologia", talvez bastará um rápido exemplo demonstrativo. São "princípios" principalmente citados como existentes, mas quase nunca sequer listados, na maior parte da literatura do campo agroecológico. Em artigo recente, ao discutir as diferenças entre a agricultura orgânica e a agroecologia, Abreu e seus colegas colaboradores arrolaram os tais princípios, fundados na sua origem bibliográfica usual e obrigatória - algum texto de Stephen Gliessman (por exemplo, GLIESSMAN, 2000). Sem discutir o conteúdo específico desse artigo, os autores mencionam que "[...] a agroecologia entendida como um estilo de agricultura pode ser mais ou menos sustentável quando é capaz de atender, de maneira integrada, aos seguintes princípios [...]: a) baixa dependência de inputs externos e reciclagem interna; b) uso de recursos renováveis localmente; c) mínimo de impacto adverso ao meio ambiente; D) manutenção em longo prazo da capacidade produtiva; e) preservação da diversidade biológica e cultural; f) utilização do conhecimento e da cultura da população local; g) satisfação 
das necessidades humanas de alimentos e renda" (ABREU et al., 2012, p. 144-145). Novamente sem poder proceder a uma minuciosa análise apenas deste trecho do artigo (agora agroecologia seria um "estilo de agricultura", uma recente noção introduzida pela Sociologia, que é também vazia em suas possibilidades interpretativas), basta apenas uma pergunta, dirigida a apenas um dos itens listados acima: qualquer agricultura que se proponha como ecológica exige a preservação ou até a ampliação da biodiversidade, seja no tocante à produção vegetal como a animal, contrariamente à tendência de uniformização da agricultura moderna, normalmente simbolizada na tendência à monocultura. Do ponto de vista ambiental, a Ecologia já demonstrou ser o padrão assentado na biodiversidade o ideal, também justificado por diversos argumentos agronômicos que aqui não precisam ser citados. Há uma implicação, contudo, que usualmente nenhum autor simpatizante da agroecologia discute: a biodiversidade dos sistemas agrícolas não apenas introduz crescente complexidade para o manejo, mas, em especial, requer muito mais intensivamente o uso da mão-de-obra no cotidiano da atividade agrícola. Portanto, tais considerações levam inevitavelmente à pergunta: como compatibilizar a exigência de mais trabalho com a diminuição do tamanho das famílias rurais, seja pela redução das taxas de natalidade ou, então, em decorrência da desistência de membros da família, notadamente os mais jovens? Esses dois processos demográficos têm sido observados em todas as regiões rurais brasileiras e, dessa forma, permaneceria o desafio: quem daria conta das tarefas inerentes à manutenção da biodiversidade dos sistemas agrícolas?

A manipulação exercida sobre grupos de técnicos (na Empresa Brasileira de Pesquisa Agropecuária - EMBRAPA e instituições estaduais de pesquisa, assim como setores das universidades) pelo "núcleo político" é também demonstrada pela gradual utilização por alguns de uma suposta nova identidade, que seria a de "agroecologistas". Trata-se de outro mecanismo subordinador usado pelo "núcleo político", visando adensar sua força política geral, quando difunde essa sugestão de identificação de todo o grupo. Mas aceitando esta autodenominação, os técnicos, de fato, vestem o chapéu de uma ideologia, no pior sentido da palavra - ou seja, 
ideologia como falseamento da realidade. Se percebessem a (constrangedora) manipulação que estão aceitando para si próprios, oriunda daquele núcleo estratégico, mas desejando não mais do que a transformação do atual padrão técnico agrícola em um tipo de agricultura ecológica (qualquer que fosse o modelo a ser seguido), prefeririam a autodenominação de "agroecólogos", pois essa seria a palavra que necessariamente conteria em si mesma a presença de uma ciência, a Ecologia e, dessa forma, um agroecólogo apenas identificaria o profissional da ciência que pretende analisar a agricultura como um agroecossistema, usando as armas analíticas, em especial, de uma ciência hoje consolidada, a Ecologia. Enquanto isso, e pelo contrário, vestir a autoidentificação de "agroecologistas" pressupõe apenas a aceitação de uma ideologia. Como a maioria das ideologias, seus objetivos são primordialmente políticos, mesmo que falsamente revestidos de alguma carapaça que se pretenda "técnico-científica". Trata-se de uma diferença semântica pequena, mas que indica um abismo analítico entre as duas palavras, além de uma brutal diferença de compreensões sobre o mundo.

Uma agroecologia que produz agroecólogos representa um genuíno esforço científico de tentar produzir conhecimento assentado no melhor da ciência existente. Em oposição, uma agroecologia que produz "agroecologistas" se distanciará sempre da ciência e apenas ampliará o número de militantes partidarizados, cujo objetivo pouco tem a ver com as realidades agrárias e o destino das famílias rurais, pois é ação que pretende, sobretudo, e primordialmente, a mudança societária.

Em síntese: agroecologia não passaria de uma palavra geral sem nenhum significado especial em si mesma, utilizada somente para reunir diferentes modelos de agricultura ecológica que busca(ra)m oferecer alternativas à agricultura moderna. Não existe um novo modelo intitulado "agroecologia", diferentes dos demais já desenvolvidos, assim como não existe a possibilidade lógica da palavra se apresentar como um conceito. Menos ainda, sugerir que agroecologia possa ser também uma via social para difundir justiça social, contestar o sistema econômico e desenvolver uma "nova sociedade" é visão de ousadia quimérica de tal envergadura que deixa pasmo perceber que muitos possam nela acreditar. 
É preciso assim separar o joio do trigo e iluminar os diferentes gatos que tentam fingir que são iguais nessa que é ainda uma sombria noite escura chamada "agroecologia brasileira".

\section{0 mito da "ciência emergente"}

Tem sido reiterado por praticamente todos aqueles que se apresentam como simpatizantes da agroecologia que essa seria uma "nova ciência" ou, como mais comumente afirmado, uma "ciência emergente". A primeira intenção da monocórdia repetição é beneficiar-se do imaginário hegemônico sobre o papel da ciência na vida moderna e sua decorrente legitimidade social. Ou, visto pelo outro lado da moeda: se uma proposta tão ambiciosa, que promete um novo formato tecnológico radicalmente distinto para a agropecuária, não se revestir dessa aura científica, quem aceitaria sequer examinar a sugestão? É um pressuposto compulsório, portanto, que a agroecologia se apresente sob tal rótulo - seria pelo menos uma "ciência emergente". Mas a agroecologia teria tais características, as quais possam identificar uma nítida trajetória nesta direção?

Por si só, esta pergunta demandaria um encorpado estudo, impossível de ser oferecido neste curto artigo. Considera-se denso porque, inicialmente, seria preciso definir até mesmo o que significa "ciência" e como interpretar seus avanços, tema que há alguns séculos produz intensos debates, especialmente no campo da Filosofia da Ciência. Não sendo viável, faz-se então necessário, pelo menos, ter um conhecimento sólido acerca dos debates ocorridos nesse campo de inquirição humana, os quais reemergiram fortemente e com notável criatividade a partir dos anos sessenta, seguindo-se às controvérsias que introduziram filósofos luminares como Popper, Kuhn, Lakatos, Feyreband, Bachelard e outros no firmamento da forte

\footnotetext{
${ }^{9}$ Abundam os exemplos da ideologização citadas, em diversas áreas do Estado brasileiro. Como ilustração, examine-se a manifestação de um "assessor especial da Secretaria Geral da Presidência da República" (!), conforme o "link" abaixo. É artigo no qual surge nitidamente esta primária natureza ideológica e a supremacia do pensamento mágico, além de chocante desinformação acerca do desenvolvimento agrícola brasileiro. Ver em:

http://www2.planalto.gov.br/consea/comunicacao/artigos/brasil-agroecologico-e-consciencia-planetaria
} 
polêmica então desencadeada, estimulando uma discussão que permanece até nossos dias. Seria igualmente requerido que esse campo do conhecimento filosófico fosse solidamente comandado pelos praticantes da agroecologia porque em quase todos os seus textos os agroecológicos insistem em afirmar com estridência a sua insatisfação com as práticas científicas do establishment e seus procedimentos canônicos, ainda que sem apontar outro caminho que pudesse substituir as correntes científicas e suas práticas atualmente dominantes. Ou, mais incisivamente: a agroecologia, tal como praticada no Brasil, tem aqui mais uma de suas chocantes fragilidades - quase todos precisam reafirmar um auto de fé, que é uma posição desqualificadora da visão e da prática da ciência estabelecida, mas não é oferecida nenhuma vertente científica em substituição, apenas uma frase vazia e retórica. ${ }^{10}$ Desse modo, a agroecologia seria uma "ciência emergente" ou "uma nova forma de fazer ciência", que seria ancorada em um novo método científico. Onde este se situa e qual a sua conformação ontológica, ninguém sabe, ninguém viu.

Usualmente, a referência de todos os simpatizantes desse campo, em textos escritos, é citar o ecólogo norte-americano Stephen Gliessman, como se a simples referência a um autor estrangeiro automaticamente garantisse alguma certeza de estar "emergindo uma ciência"11. Aqui, novamente, se encontra uma atitude absurdamente acrítica, pois Gliessman, de fato, não criou ciência alguma, sequer um conceito ou teoria. O que seus escritos vêm propondo, não mais do que isso, é uma espécie de "conclamação", exortando seus colegas para se esforçarem a criar

\footnotetext{
10 Nos textos sobre agroecologia, quando muito a crítica à "ciência estabelecida" vem acompanhada de uma referência a Fritjof Capra e (com raridade) alguns mais sofisticados também citam Bruno Latour (embora sempre sem comentar mais longamente).

11 Também Miguel Altieri (ALTIERI, 1987) é às vezes referenciado, como o outro autor que teria oferecido um "fundamento científico" à agroecologia. Nada mais distante da realidade. Altieri conhece (e muito bem) os sistemas agrícolas de comunidades indígenas andinas, onde se formaram em séculos extraordinários agroecosistemas, de manejo complexo e demonstrativos de espetacular engenhosidade humana. Mas seus livros e artigos jamais foram teóricos ou conceituais, e apenas descritivos de tais sistemas de produção. Constrange o comportamento colonizado de tantos colegas brasileiros, tratando-o como alguém que tivesse a capacidade de interpretar 0 desenvolvimento agrário e agrícola no Brasil, tema que ele desconhece completamente. Resta, portanto, apenas o simplório esforço "teorizador" de Stephen Gliessman, repetido por todos como o proponente da "ciência da agroecologia".
} 
o que ele propõe como uma ecologia dos sistemas agroalimentares, ou mais precisamente, quando enfatiza que:

[...] uma das mais completas definições de agroecologia, atualmente, é a ecologia do sistema alimentar [...] [Ela] tem a meta explícita de transformar os sistemas alimentares na direção da sustentabilidade, na qual existe um equilíbrio entre a adequação ecológica, a viabilidade econômica e a justiça social [...] Mas, para alcançar esta transformação, a mudança é necessária em todas as partes do sistema alimentar, da semente e o solo e até a mesa [dos consumidores] (GLIESSMAN, 2013a, p. 20, grifo do autor).

Nenhum dos textos de autoria desse ecólogo vinculado à Universidade da Califórnia vai além de frases genéricas como essas acima citadas. Em nenhuma parte existe um conceito propriamente dito, menos ainda uma teoria. Gliessman, inclusive, é honesto o suficiente para enfatizar algumas lacunas, quando alerta que " [...] as fundações ecológicas [da agroecologia] são claras, mas os componentes sociais e políticos onde a mudança social é mais necessária, são muito menos [claros]" (GLIESSMAN, 2013b, p. 1).

É, portanto, surpreendente que alguns autores brasileiros, sem a mesma honestidade intelectual, apenas repitam monotonamente, como uma espécie de mantra religioso, que existiria um "conceito" ou uma "teoria" sobre a agroecologia, mas sem jamais indicar esta fundação interpretativa que estaria disponível ou embrionária. Por que a omissão?

$\mathrm{Na}$ impossibilidade de uma longa digressão analítica sobre o tema, oferecendo uma leitura exegética de diversos textos principais, por falta de espaço neste curto e introdutório artigo, utilizo um documento paradigmático, o qual deveria representar o sumo da "defesa científica" da agroecologia no Brasil - o "Marco referencial em agroecologia”, concluído pela EMBRAPA em 2006. É o documento ideal para esse fim porque foi tornado público e assumido formalmente pela mais importante instituição brasileira de pesquisa agrícola, cuja missão principal é, precisamente, oferecer formatos tecnológicos correspondentes às realidades dos sistemas agrícolas do país que sejam cientificamente validados. Além disso, o documento é assinado por nada menos do que 16 técnicos de alta qualificação 
acadêmica, os quais teriam sido apoiados por 339 colaboradores (!) da mesma empresa. Assim, tudo somado, as respostas às tantas indagações sobre a agroecologia e seu impressionante déficit científico e prático poderiam (e deveriam) encontrar respostas e explicações adequadas nesse texto (EMBRAPA, 2006).

Infelizmente, nenhuma dessas expectativas é atendida, após um criterioso exame do "Marco". O documento é analiticamente pobre e insuficiente, demasiadamente superficial e aparenta até certa preguiça, demonstrando não ter motivado esforços analíticos de maior significação. Principalmente, não responde, praticamente, a nenhuma das inúmeras perguntas que demandam esclarecimento, no sentido de oferecer alguma inteligibilidade à agroecologia. Causa alguma surpresa, inclusive, que o prefácio do documento seja assinado pelo atual coordenador de uma minúscula ONG anti-sistêmica, a AS-PTA (p. 15-20), mais uma vez indicando, com meridiana clareza, a manipulação operada pelo que foi aqui chamado de "núcleo político" sobre os demais "núcleos". Nem mesmo o próprio presidente da EMBRAPA na ocasião percebeu tal subordinação explicitada ante tal fato, liberando com sua assinatura o apoio institucional. Com um histórico de mais de vinte anos de crítica ao padrão tecnológico da agricultura moderna e uma visão política anticapitalista, é incompreensível que um documento oficial da EMBRAPA tenha permitido que um destacado integrante do "núcleo político" pudesse abrir o "Marco referencial". É uma aberrante contradição porque é ONG que sempre exerceu a crítica radical à agricultura moderna e, assim, como explicar que abra uma publicação oficial da EMBRAPA, a empresa pública que promoveu nos últimos quarenta anos (e com enorme êxito) exatamente o padrão técnico moderno e sua implantação nas regiões agrícolas do país. Como interpretar esse fato surreal, senão como a resultante bem sucedida de manobra de natureza essencialmente política?

Sucintamente, alguns focos mais salientes se destacam, na análise do documento. Primeiramente, o "Marco referencial" oferece uma reveladora contradição interna. Os autores corretamente apontam (ainda que muito brevemente) a existência histórica de diversas "agriculturas de base ecológica" (p. 23), inclusive citando os proponentes principais desses diferentes tipos de tentativas 
realizadas, durante o Século $\mathrm{XX}$, de desenvolver outros formatos tecnológicos para os sistemas agrícolas que fossem, em alguma medida, ecológicos (modelos tecnológicos pioneiramente descritos em Ehlers, 1996). Mas, como as premissas constitutivas desses distintos enfoques são muito diferenciadas entre si, uma vez concretizadas, é preciso reconhecer que propor um conceito destinado a subsumir todas as propostas de agricultura ecológica até aqui apresentadas é uma impossibilidade objetiva, em face de tais diferenças. A sugestão, portanto, de um termo (agroecologia) que possa dar conta de todos aqueles enfoques pioneiros é logicamente impossível - se os pressupostos daqueles enfoques antecedentes são, alguns deles, incompatíveis e contraditórios entre si, como um "conceito superior" poderia anular aquelas premissas antinômicas entre si? Em consequência, a agroecologia não pode deixar de ser tão somente ou (a) apenas "mais um enfoque" que viesse a se juntar às propostas anteriores, definida sob alguma especificidade inovadora, (o que não é), ou (b) o que, de fato, a agroecologia é, conforme sugerido na primeira seção deste artigo, não mais do que uma "palavra guarda chuva" que apenas tenta abrigar sob si as diferentes visões sobre a ecologização da agricultura. Seria apenas uma simples noção classificatória ou um termo, sem nenhuma importância conceitual, que incluiria sob si os diferentes modelos tecnológicos que propuseram nos últimos cem anos algum tipo de reorganização da agricultura. E essa classificação teria apenas um outro polo: a agricultura moderna. Assim posto, a agroecologia jamais poderia ser um conceito, menos ainda uma teoria (e, portanto, também não contendo "princípios").

A tentativa de insistir que, pelo contrário, a agroecologia possa ser uma "noção englobante", abrigando as anteriores propostas de ecologização da agricultura conceitualmente, apenas reforça a tese principal deste artigo. Tal como vem sendo oferecida a agroecologia no caso brasileiro, trata-se, em especial, de uma tentativa política de evitar a fragmentação decorrente da existência daquelas distintas escolas de agricultura ecológica, criando uma (falsa) imagem de unidade sobre concepções acerca da transformação ecológica dos sistemas agrícolas. 
Em segundo lugar, o "Marco referencial" abunda em frases particularmente retóricas, o que surpreende, por ser um documento da EMBRAPA, que deveria exigir rigor conceitual e pelo menos algum tipo de aderência canônica às práticas da ciência. Ou será que seus autores imaginam ser possível alguma prática científica (qualquer que seja) sem algum ritual canônico? Como supor que o documento possa ser recepcionado com seriedade quando abundam frases retóricas, quase surrealistas, as quais afirmam que a agroecologia teria sua origem "no estudo das práticas camponesas das agriculturas tradicionais e numa integração interdisciplinar", complementando ainda que ela "busca, por meio de uma concepção holística, entender as relações derivadas da co-evolução entre as culturas humanas e a natureza, para desenhar, mediante o fortalecimento de processos de ação social coletiva, estilos de agricultura de alta renovabilidade e estratégias endógenas de desenvolvimento rural" (p. 31)? É meta que, do ponto de vista sociológico, não passa de um evidente despautério, como se processos de ação coletiva pudessem ser "fortalecidos" a partir de meros desejos.

Em outra parte, o primitivismo analítico desse exercício se manifesta com frases que esvaziam os argumentos. À página 24, por exemplo, os autores pontificam que "o caráter local é que dará a feição concreta de seus princípios [da agroecologia]", ainda enfatizando que "é a realidade socioeconômica e ecológica local que define a melhor forma de aplicação da teoria, exigindo ajustes finos a cada situação" (grifo acrescido). Tal teoria nunca é oferecida aos interessados, mas os autores sequer perceberam que essa defesa que fazem da "primazia do local" os situa em campo analítico ainda mais rebaixado e empobrecido do que até mesmo a visão popular de ciência que a Filosofia da Ciência intitulou de "indutivismo ingênuo". Este último, pelo menos, aceitaria a existência de proposições universais extraídas exclusivamente da observação, mas sempre a partir de grandes amostras da realidade, enquanto, no geral, os textos agroecológicos reduzem ao mínimo as singularidades empíricas que sustentariam a possibilidade de propor alguma extrapolação universal, em função de sua argumentação em favor do localismo. A vasta maioria dos textos agroecológicos pretende oferecer um "conhecimento novo" 
meramente a partir de pouquíssimos casos concretos, sem nenhuma representatividade amostral. Não sem surpresa, são estudos que também ressaltam, com alguma arrogância, a desnecessidade do conhecimento estatístico consagrado na ciência agronômica. É importante enfatizar que o indutivismo ingênuo foi devidamente demolido meio século atrás, pelo menos, pelos autores que se dedicam seriamente ao estudo da ciência e suas particularidades (CHALMERS, 1978, p. 1-72).

Finalmente, o documento também é marcado por um grande número de afirmações visivelmente ingênuas, o que também causa certo espanto. Diversas afirmações contidas no "Marco referencial" são chocantemente pueris ou desinformadas. São inúmeros os exemplos, que variam desde frases de otimismo irrealista [“[...] está em curso um intenso debate conceitual sobre a Agroecologia”, p. 22] às proposições que afirmam o inexistente, tanto na literatura como no próprio documento: "Sendo a agroecologia um referencial teórico..." (p. 24), ou "A agroecologia é considerada como ciência emergente, orientada por uma nova base epistemológica e metodológica" (p. 25), ou ainda "[...] podemos dizer que Agroecologia - como uma abordagem científica..." (p. 36). Em nenhum parágrafo do "Marco", contudo, apresentase o referencial teórico ou sua "base epistemológica e metodológica", deixando seus leitores intrigados. Afinal, o que se pretendeu realmente com este documento?

Um exemplo de uso paroxístico do recurso retórico se encontra exatamente no único parágrafo do "Marco referencial" que se aproxima do significado de agroecologia defendido por seus proponentes. Segundo os autores, a agroecologia existe para:

[...] demarcar um novo foco de necessidades humanas, qual seja, o de orientar a agricultura à sustentabilidade, no seu sentido multidimensional. Num sentido mais amplo, ela se concretiza quando, simultaneamente, cumpre com os ditames da sustentabilidade econômica [...], ecológica [...], social (inclusão das populações mais pobres e segurança alimentar), cultural (respeito às culturas tradicionais), política (organização para a mudança e participação nas decisões) e ética (valores morais transcendentes) (EMBRAPA, 2006, p. 22-23).

A citação é inacreditável, se analisada friamente e com o mínimo de racionalidade lógica, pois fica desnudado o desconhecimento dos autores acerca do 
funcionamento de um setor econômico chamado "agricultura" nas modernas sociedades capitalistas. Dezesseis autores principais e dezenas de colaboradores da empresa sancionariam essa frase? Se acreditarem no que escreveram, seriam capazes de apontar um único estabelecimento rural brasileiro que preencha aqueles requisitos exigidos pela agroecologia, inclusive portadores dos misteriosos "valores morais transcendentes"?

\section{Agroecologia: um jogo de cena?}

À luz da brevíssima descrição histórico-factual arrolada na primeira seção deste artigo e, também, considerando-se que agroecologia não encerra o menor lustro científico, por mais superficial que possa vir a ser, conforme discutido na seção anterior, o que então pretende o "campo agroecológico"12 no Brasil? A resposta a essa pergunta somente pode ser iniciada com um "depende". Isso porque seria preciso, inicialmente, iluminar qual dos subgrupos desse campo estaria sendo analisado, entre aqueles três principais citados na primeira seção desse texto.

Se a resposta for referida ao "núcleo político" da operação intitulada "agroecologia", a resposta é óbvia: não se trata de nenhum objetivo técnico, científico ou agronômico. Menos ainda, não se trata de qualquer preocupação sincera com o destino dos pequenos produtores. Trata-se, meramente, de manter uma crítica anticapitalista, usando-se para tanto a camuflagem da crítica à agricultura moderna. Como antes citado, em sociedades democráticas, assumir essa crítica não deveria causar qualquer sobressalto ou incômodo pessoal, pois é legítima e parte do jogo das disputas políticas. O que falta apenas, conforme também antes referido, é a honestidade dos atores (e autores) desse subgrupo assumir claramente

\footnotetext{
12 O uso do termo "campo", neste trabalho, inspira-se no conceito proposto por Bourdieu. Se seguido rigorosamente, este seria conceito inadequado para dispor os agentes ligados à agroecologia em um dado espaço social, pois campo, em Bourdieu, exige o posicionamento dos agentes, o que é a priori fixado pelas "disposições duráveis" do sistema de habitus, a distribuição de capitais e as práticas vigentes na sociedade. Não obstante esta advertência, poderá ser útil pensar a comunidade de agroecologistas tentativamente como um "campo", na acepção de Bourdieu, sobretudo para prefigurar as relações de poder entre os grupos e agentes participantes e assim identificar mais visivelmente as hierarquias esboçadas neste artigo.
} 
esta crítica - não à agricultura moderna, mas ao regime econômico que ordena a sociedade. No caso brasileiro, essa desonestidade política é nitidamente assumida nos textos da AS-PTA, os quais, quase nunca, explicitam suas posições políticas e, pelo contrário, usam os temas técnicos (o debate sobre os transgênicos, por exemplo) para meramente desenvolver ações políticas anticapitalistas. Assim afirmado, a frase parece irresponsável, mas bastaria examinar a maior parte de suas publicações para verificar facilmente serem esses os objetivos daquela ONG.

Por que esse ocultamento? Ora, a resposta é igualmente óbvia: em face do conservadorismo político da sociedade brasileira, da imaturidade democrática que nos rege, além dos interesses partidários em jogo, certamente julgam os membros desse "núcleo" ser mais oportuno manter uma posição disfarçada e insistir no ilusionismo manipulador de suas manifestações. Mas, à luz da liberdade política da qual (felizmente) usufruímos, esse é um comportamento excêntrico e estapafúrdio, e sua reiteração não se justifica. Por que os militantes dessa ONG (e seus simpatizantes no mundo da academia universitária) não se inspiram no comportamento de um autor que é igualmente anticapitalista, mas se assume honestamente como tal? O sociólogo espanhol Eduardo Sevilla Guzmán, tido como um dos principais nomes da agroecologia, não tem pruridos ideológicos de difundir com clareza suas intenções, ao assinar um artigo onde aponta a evolução das principais noções que, segundo ele (e o coautor do artigo) formariam o "emergente campo da agroecologia" a partir da década de 1980.

Sem discutir diversos outros aspectos do artigo, que é fortemente controverso e marcado por equívocos populistas, Guzmán aponta no artigo o que intitula de "visões competidoras" sobre a organização social, insistindo que, nos anos oitenta um conjunto de autores contribuiu para garantir um salto na evolução das ideias que - assegura Guzmán - teriam criado uma teoria social ambiental e também a agroecologia. Além disso, indica sem hesitações que uma dessas contribuições originou-se no "pensamento marxista e libertário" e, ato contínuo, cita a si mesmo e sua bibliografia como tendo sido o principal nome sob aquela perspectiva. Um anarquista convicto, Guzmán não se esconde em eufemismos e falsas teorizações, 
como o fazem quase todos os brasileiros integrantes do "núcleo" acima citado (GUZMÁN; WOODGATE, 2013).

Mas é preciso comentar sobre o segundo grupo (o "núcleo operacional"), integrado especialmente por pesquisadores de diferentes instituições de pesquisa agrícola, da EMBRAPA às instituições estaduais, diversos profissionais dos serviços de ATER (públicos e das ONGs) passando por alguns setores universitários, usualmente ligados às escolas de Agronomia. São, no geral, técnicos que professam muito confusamente o que entendem por agroecologia e, quase invariavelmente, desenvolvem esforços de pesquisa que não resistem à menor análise, por serem inconsistentes e metodologicamente falhos. Como prova empírica da vacuidade conceitual do termo, as percepções desses profissionais sobre a agroecologia materializam uma incompreensível cacofonia, já que nenhum deles repete a mesma conceituação de outro participante do campo. São técnicos que não se preocupam com validação científica, não se referem aos debates sobre a ciência e sua natureza, desprezam abertamente a exigência de representatividade empírica e, como foi antes citado, embarcam em exercícios que julgam ser científicos, embora não passem de manifestações quase anedóticas ${ }^{13}$.

No geral, os integrantes desse segundo subgrupo comandam uma formação extremamente rasa em Ciências Sociais, ainda que pontifiquem, com frequência, sobre a sociedade e os comportamentos sociais (especialmente dos produtores rurais). São assim facilmente capturados em armadilhas políticas desenvolvidas pelo "núcleo político", ainda que não as percebam como tal. Não podendo ser discutido mais extensamente, cito apenas o exemplo da recente lei antes referida (agosto de 2012) que exige que a definição de produção "de base agroecológica" inclua a expressão "justiça social". Certamente, os integrantes desse segundo grupo ignoram

${ }^{13}$ Como toda generalização sobre os comportamentos sociais, existem as exceções notáveis e que merecem irrestrita admiração. São diversos colegas que o autor deste artigo gostaria de citar nominalmente, pois técnicos profundamente dedicados à construção de uma agricultura que possa ser em alguma medida ecológica, mas igualmente preservando as chances de produção de renda para as famílias rurais. E sem por em risco as famílias rurais em nome de aventuras irresponsáveis. Não podendo citar nomes, com este registro se acentua o conhecimento sobre essas exceções. 
por completo que existe um vastíssimo campo teórico no interior da Filosofia Política que jamais chegou a nenhum acordo sobre o significado de justiça social. Sendo assim, por que incluir a expressão como um dos requerimentos da agroecologia? Se sequer os especialistas no assunto (cientistas políticos, filósofos) alcançaram algum consenso mínimo, ainda que sejam estudiosos debatendo intensamente e sem sofrer interdições, porque os aderentes da agroecologia podem supor que incluir a exigência de justiça social será um fator de maior coesão conceitual? Ainda pior, por que incluir aquela polêmica expressão em uma lei? Seria possível listar ad nauseam as inconsistências e puerilidades da literatura e os incontáveis exemplos relacionados à agroecologia no Brasil, um exercício que apenas causa pasmo. Não parece crível que recursos públicos, financeiros e humanos, possam estar sustentando essa sequência assombrosa de infantilidades.

É preciso citar ainda que a "marcha da agroecologia" no Brasil conta igualmente com um terceiro subgrupo, o "núcleo de militantes", formado normalmente por segmentos estudantis ingênuos e que apenas se curvam às diretrizes de suas lideranças, sem nenhuma maturidade intelectual e capacidade analítica para avaliar o que estão fazendo. A eles se unem, ocasionalmente, pequenos grupos de outros militantes, aqueles ligados ao MST, conforme antes referido.

Em síntese: se falta ética e honestidade política entre os integrantes do primeiro subgrupo, sobra ingenuidade no "núcleo operacional", enquanto o "núcleo de militantes" não é mais do que a infantaria cega a serviço do "núcleo político". Se a maioria dos praticantes do campo agroecológico integrantes desse segundo subgrupo não se esforçar mais para analisar com rigor o seu próprio trabalho e a fragilidade sobre a qual assentam seus esforços, procurando separar-se claramente da subordinação imposta pelo primeiro "núcleo", permanecerá esta situação de manipulação apontada nesse artigo. Um significativo número de profissionais das instituições de pesquisa, que resiste à reflexão crítica e aceita passivamente o jargão falsamente técnico do primeiro subgrupo (pois é especialmente movido por intenções políticas), apenas adensa a falsa imagem de uma legitimidade "científica" 
de uma palavra que foi tornada mágica - a agroecologia. É preciso muito mais esforço crítico dos profissionais desse segundo grupo, para poderem, de fato, avançar esforços propriamente científicos na construção de formatos tecnológicos ecológicos para os sistemas agrícolas, além da mera retórica que ora caracteriza praticamente tudo o que é feito no Brasil sob essa palavra e seus correlatos. A pronta e fácil aceitação da agroecologia como um suposto conceito que englobaria diferentes visões sobre vias tecnológicas destinadas a concretizar modelos de agricultura ecológica demonstra a ingenuidade política desse segundo subgrupo e, na realidade, impede que colaborem com qualquer avanço concreto em termos propriamente agronômicos e científicos. Surpreende que os profissionais envolvidos não percebam esse jogo de cena ora em andamento.

Finalmente, permanece sem resposta adequada uma pergunta que deveria ser relevante: por que não desenvolvemos no Brasil um debate fraterno, sério e rigoroso, sem vetos prévios, sobre o assunto? Por que os seguidores da agroecologia preferem o jogo da vitimização (seriam "perseguidos pelo sistema") e se ocultam em mistificações de todas as ordens, para fugir ao debate honesto e franco? Suas ações são imensamente facilitadas, por outro lado, pela omissão de instituições que deveriam confrontar democraticamente e com limpidez analítica essa marcha da insensatez. Por que o Ministério da Agricultura e a EMBRAPA, por exemplo, não realizam esforços metódicos e cientificamente irrepreensíveis de discutir esta palavra mágica e verificar se, de fato, representa algum caminho que possa ser oferecido com segurança aos produtores rurais? Pelo contrário, é melancólico perceber que a intimidação política e partidária amesquinha aquelas instituições, que se refugiam na omissão. Ante a passividade, os integrantes do campo agroecológico não são instados sequer a explicarem o que os move e conseguem até mesmo a institucionalização de seus esforços, como o comprova a recente lei assinada - ou seja, institucionaliza-se o que ainda não existe (nem como ciência, nem como prática social, nem mesmo como movimento social). ${ }^{14}$

\footnotetext{
${ }^{14}$ Wezel et al. (2009) julgam que o crescimento do campo agroecológico já permitiria divisar essas três divisões entre os seus praticantes.
} 
Adicionalmente, no caso da EMBRAPA, conforme brevemente discutido na seção anterior, ainda se estimula que um conjunto de técnicos da empresa, quase todos integrantes do chamado "núcleo operacional" (ou seja, manipulados pelo "núcleo político"), ainda usem os espaços públicos e os fundos da sociedade para realizar ações anticientíficas no âmbito da principal empresa de pesquisa agrícola do país. Macondo e o "real maravilhoso" não fariam melhor".

\section{Conclusões}

Ainda que reconhecendo ser controversa essa conclusão, é inescapável afirmar com todas as letras que a agroecologia, tal como vem sendo difundida no Brasil, é uma fraude. Não se trata nem de uma operação científica, nem de práticas agrícolas que possam ser oferecidas aos produtores como um "formato tecnológico alternativo" e, menos ainda, de um movimento social, pois essa expressão tem um conteúdo sociológico relativamente preciso. Pelo menos no Brasil, tem sido, em especial, um embuste que assume proporções crescentes, além de ser movido também por vetores inaceitáveis, do ponto de vista democrático. É assim porque utiliza fundos públicos, com diversas instâncias do Estado brasileiro envolvendo recursos, financeiros e humanos, para difundir algo que não tem interpretação ou legitimidade científica, mas apenas mal dissimulados objetivos políticos. Como discutido sinteticamente neste artigo, é ação que, na maior parte das situações e das ações individuais, não contém má fé, mas apenas a ingenuidade de um conjunto, sobretudo, de técnicos desinformados, boa parte deles se prestando ao humilhante papel de marionetes de uma estratégia comandada por pequeno grupo

\footnotetext{
${ }^{15} \mathrm{O}$ "real maravilhoso" é um gênero literário herdado do surrealismo e típico de alguns autores latinoamericanos, celebrado, particularmente, no famoso livro "Cem anos de solidão", do colombiano Gabriel Garcia Marquez, originalmente publicado em 1967. Macondo é a fictícia cidade onde se desenvolve a trama narrativa. Segundo outro autor que celebrou o gênero, o guatemalteco Alejo Carpentier, o real maravilhoso seria tudo aquilo na vida social que é extraordinário, acrescentando que "lo extraordinário no es bello ni hermoso por fuerza. Ni es bello ni feo; es más que nada asombroso por lo insólito. Todo lo insólito, todo lo asombroso, todo o que sale de las normas establecidas es maravilloso" (Carpentier, A. Ensayos selectos. Buenos Aires: Corregidor, 2007, p. 143). Carpentier é o autor de outro clássico do gênero, $O$ reino deste mundo, originalmente publicado em 1949.
} 
de ideólogos e operadores do campo político. O mais deletério dessa ação é o chocante uso que se faz da incredulidade de algumas centenas de pequenos produtores, envolvidos em uma narrativa que parece sedutora e que thes é vendida como uma espécie de "salvação". Concretamente, contudo, é um ilusionismo (falsamente técnico) que apenas amplia a probabilidade de marginalização econômica dos estabelecimentos rurais atraídos por este conto da carochinha. A perversidade de tal oferta tecnológica é igualmente reforçada porque vivemos atualmente um novo padrão econômico e financeiro no campo brasileiro, que vem acentuando notavelmente o acirramento concorrencial e, como tal, oferecer caminhos tecnológicos não validados e largamente incompletos àquele grupo de produtores, ante tal situação ora vivida, é um ato de absurda irresponsabilidade. Comprometerá irremediavelmente as chances de permanência na atividade desses produtores, forçando-os ao abandono ${ }^{16}$.

Conforme apontado neste artigo, são necessárias urgentes iniciativas no sentido de separar o joio do trigo e, assim, realizar esforços sérios e consequentes, assentados em boa ciência, que possam oferecer em escala crescente as saídas tecnológicas (mas viáveis economicamente) que permitam aos agricultores moradores nos estabelecimentos de menor porte econômico produzir com produtividade e lucratividade, simultaneamente à maximização no uso de seus parcos recursos naturais e mantidos os imperativos ambientais que preservem a sustentabilidade de sua capacidade produtiva. A combinação entre objetivos produtivos e ambientais, portanto, é uma necessidade de urgente concretização e deveria informar intensos esforços da pesquisa agrícola brasileira. Mas, para isso, é preciso desintoxicar tais esforços da primária ideologização que vem conduzindo boa parte das iniciativas e projetos ora em desenvolvimento e, sobretudo, iluminar esta noite escura assumida pela expressão "agroecologia" no Brasil, o que permitiria separar a pesquisa séria, bem intencionada e plural dos comportamentos sociais que apenas repetem jargões presumivelmente científicos, para dar algum lustro de legitimidade social, enquanto seus objetivos, de fato, são outros.

\footnotetext{
${ }^{16}$ Sobre este novo padrão de crescimento da agricultura, consulte-se Buanain et al, 2013.
} 
Ciência e política não podem ser separadas radicalmente, pois a vida social é política, por definição, assim como o são as práticas científicas. O mundo do laboratório e da experimentação não está descolado do mundo social e, portanto, a frase "tudo é político" não representa, de fato, nenhum exagero retórico, mas apenas a realidade da sociedade humana. Mas a separação entre ciência e o binômio ideologia-partidarização é possível, pelo menos no campo do conhecimento - basta existir honestidade intelectual. $\mathrm{O}$ caso da disseminação da expressão citada (e seus correlatos), como vem ocorrendo no Brasil nos anos mais recentes, sugere exatamente ser essa a postura que falta a uma parte dos praticantes do campo agroecológico. A transição à qual almejam a maioria de seus proponentes tem méritos inegáveis e é necessária para a construção de um padrão tecnológico que preserve recursos naturais e gradualmente concretize $o$ ideal da sustentabilidade. Mantido, contudo, o mundo da esperteza política, da manipulação ideológica, do charlatanismo e da ignorância científica, nada se construirá nessa direção.

\section{Referências}

ABREU, L. et al. Relações entre agricultura orgânica e agroecologia: desafios atuais em torno dos princípios da agroecologia. In: Desenvolvimento e meio ambiente, v. 26, p. 143-160. Curitiba: UFPr, 2012.

ALTIERI, M. Agroecologia. As bases científicas da agricultura sustentável. Rio de Janeiro: AS-PTA, 1987.

BUAINAIN, A. M. et al. Sete teses sobre o mundo rural brasileiro. In: Revista de Política Agrícola, ano XXII, n. 2, p. 105-121. Brasília: MAPA, 2013.

CHALMERS, A. F. What is this thing called science? The Open University Press, 1987.

EBDA. EMPRESA BAIANA DE DESENVOLVIMENTO AGRÍCOLA. Palestra de agroecologia. Definição. Morpará (Bahia), VI Feira da Agricultura familiar, 27 de agosto (Escritório local de Ibotirama, Empresa Baiana de Desenvolvimento Agrícola), 2011. 
EHLERS, E. Agricultura sustentável: origens e perspectivas de um novo paradigma. São Paulo: Livros da Terra, 1996.

EMATER. EMPRESA DE ASSISTÊNCIA TÉCNICA E EXTENSÃO RURAL. Relatório de atividades 2012. Porto Alegre: EMATER/RS, 2013.

EMBRAPA. EMPRESA BRASILEIRA DE PESQUISA AGROPECUÁRIA. Marco referencial em agroecologia. Brasília: EMBRAPA, fevereiro. 2006. Disponível em $<$ http://www.embrapa.br/publicacoes/institucionais/titulos-avulsos/marco_ref.pdfL>. Acesso em: julho/2013.

GLIESSMAN, S. Agroecology: growing the roots of resistance. In: Agroecology and Sustainable Food Systems, n. 37, p. 19-31, 2013a.

Agroecologia. Processos ecológicos em agricultura sustentável. Porto Alegre: UFRGS, 2000. (Série Estudos Rurais).

. Editorial. In: Agroecology and Sustainable Food Systems, n. 37, p. 1-2, 2013b.

GUZMÁN, E. S.; WOODGATE, G. Agroecology: foundations in agrarian social thought and sociological theory. In: Agroecology and Sustainable Food Systems, n. 37, p. 32-44, 2013.

IPEA. INSTITUTO DE PESQUISA ECONÔMICA APLICADA. O comércio internacional e a sustentabilidade socioambiental no Brasil. n. 79. Brasília: IPEA, 2011. (Comunicados do IPEA).

MARTINE, G.; GARCIA, R. N. Os impactos sociais da modernização agrícola. Rio de Janeiro: Caetés, 1987.

MILLS, C. WRIGHT. The Sociological Imagination. London: Oxford University Press, 1959.

WEZEL, A. S. et al. Agroecology as a science, a movement and a practice. A review. In: Agronomy for Sustainable Development, n. 29, p. 503-515, 2009. 